\title{
Kuat Tekan Beton dan Nilai Penyerapan dengan Variasi Perawatan Perendaman Air Laut dan Air Sungai
}

\author{
(Compressive Strength and Absorption on Concrete with Sea and River Water Curing Variations)
}

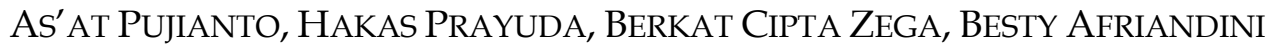

\begin{abstract}
ABSTRAK
Penelitian ini membahas pengaruh dari perawatan beton menggunakan air laut dan air sungai terhadap karakteristik beton. Tujuan dari penelitian ini untuk menjelaskan pengaruh dari jenis air pada perawatan beton, khususnya pada beton yang digunakan yang berhubungan langsung dengan air. Pada penelitian ini menggunakan tiga jenis produk semen yaitu Holcim, Tiga Roda dan Gresik dengan total 12 variasi dan 108 benda uji berbentuk silinder berdiameter $15 \mathrm{~cm}$ dan tinggi $30 \mathrm{~cm}$. Seluruh variasi menggunakan standar mix design yang sama dengan 6 variasi menggunakan perbedaan jumlah superplasticizer dan 6 variasi menggunakan bahan tambah fly ash. Pengujian yang dilakukan berupa pemeriksaan workabilitas, kuat tekan dan nilai penyerapan. Hasil pada pengujian ini menunjukkan bahwa nilai workabilitas pada beton menggunakan superplasticizer lebih baik dibandingkan beton menggunakan bahan tambah fly ash. Hasil kuat tekan menunjukkan bahwa seluruh benda uji dengan perawatan air laut lebih tinggi dibandingkan dengan beton menggunakan perawatan air sungai. Sedangkan nilai penyerapan menunjukkan bahwa pada umur 28 hari dengan menggunakan air laut menghasilkan nilai yang lebih tinggi dibandingkan perawatan menggunakan air sungai.
\end{abstract}

Kata kunci: workabilitas, kuat tekan, air laut, air sungai, variasi perawatan

\section{ABSTRACT}

This study will discuss the effect of concrete treatment using sea water and river water on the characteristics of concrete. The purpose of this study was to determine the effect of water types in concrete treatment, especially for concrete used directly in contact with water. In this study three types of cement brands, Holcim, Tiga Roda and Gresik were used with a total variation of this study as many as 12 with the number of test specimens of 108 cylindrical concrete measuring $15 \mathrm{~cm}$ in diameter and $30 \mathrm{~cm}$ in height. All variations use the same mix design and then modified with 6 variations using super-plasticizer added material while the remaining 6 variations use material added admixture in the form of fly ash which then carried out workability testing, compressive strength and percentage of absorption. The results of this study indicate that the level of concrete workability using superplasticizer added material is much better than using materials added by fly ash. The results of the compressive strength obtained showed that almost all specimens with soaking seawater had a higher compressive strength than concrete with treatment with river water. Absorption results show that at 28 days the seawater absorption rate is greater than river water.

Keywords: workability, compressive strength, sea water, river water, curing condition

\section{PENDAHULUAN}

Bangunan air merupakan salah satu aspek penting dalam pertumbuhan infrastrutktur dan ekonomi. Indonesia yang merupakan negara kepulauan dan negara agraris tentunya tidak akan terlepas dari infrastruktur bangunan air. Sebagai contoh, pelabuhan merupakan salah satu jenis infrastruktur yang penting untuk menunjang aktifitas masyarakat di Indonesia, selain ini jembatan dan bendungan juga contoh bangunan yang selalu berhubungan langsung 
dengan air yang merupakan infrastruktur penting dalam perkembangan ekonomi.

Bangunan-bangunan di Indonesia saat ini masih sangat di dominasi oleh konstruksi beton bertulang, termasuk pembangunan pelabuhan dan jembatan. Tentunya material yang digunakan dalam pembangunan bangunan khusus ini perlu menjadi perhatian agar menghasilkan kualitas bangunan yang sesuai dengan spesifikasi.

Dalam penelitian ini akan menganalisis nilai workability, nilai kuat tekan dan nilai penyerapan beton dengan menggunakan perawatan dari air laut dan air sungai dengan tiga merk semen yang berbeda serta menggunakan bahan tambah adiktif dan admixture.

Penelitian mengenai pengaruh jenis perawatan beton menggunakan air yang bervariasi sudah pernah dilakukan sebelumya. Hunggurami dkk, (2014) melakukan penelitian mengenai pengaruh masa perawatan menggunakan air laut terhadap kuat tekan dan absorpsi beton, hanya saja pada penelitian ini masih menggunakan beton normal tanpa menggunakan bahan tambah. Hendriyani dkk, (2016) melakukan penelitian mengenai pengaruh jenis air pada perawatan beton terhadap kuat tekan beton, melalui penelitian ini menjelaskan bahwa beton dengan perawatan air tawar menghasilkan kuat tekan lebih kecil dari pada menggunakan parawatan air laut. Prayuda dan Pujianto (2018) meneliti pengatuh perawatan (curing) perendaman air laut dan air tawar terhadap kuat tekan beton.

Penelitian mengenai penggunaan fly ash sebagai bahan tambah dalam beton juga sudah sering dilakukan sebelumnya. Ervianto dkk, (2016) melakukan penelitian mengenai kuat tekan beton mutu tinggi menggunakan bahan tambah fly ash dan zat adiktif (Bestmittel), melalui penelitian ini menunjukkan bahwa kuat tekan tertinggi menggunakan bahan tambah fly ash sebesar 5\%.

\section{Kuat Tekan Beton}

Beton adalah campuran antara semen portland atau semen hidrolik yang lain, agregat halus, agregat kasar dan air, dengan atau tanpa bahan tambahan yang membentuk massa padat (BSN, 2002). Seiring dengan penambahan umur, beton akan semakin mengeras dan akan mencapai kekuatan rencana (f'c) pada usia 28 hari. Beton memiliki daya kuat tekan yang baik oleh karena itu beton banyak dipakai atau dipergunakan untuk pemilihan jenis struktur terutama struktur bangunan, jembatan dan jalan.

Perbandingan campuran, cara pencampuran, cara mengangkut, cara mencetak, cara memadatkan, dan sebagainya akan mempengaruhi sifat-sifat beton (Samekto dan Rahmadiyanto, 2001).

Menurut (Tjokrodimuljo, 2007) beton memiliki beberapa kelebihan antara lain sebagai berikut ini.

a Harga yang relatif lebih murah karena menggunakan bahan-bahan dasar yang umumnya mudah didapat di berbagai daerah di Indonesia.

b Termasuk bahan yang awet, tahan aus, tahan panas, tahan terhadap pengkaratan atau pembusukan oleh kondisi lingkungan, sehingga biaya perawatan menjadi lebih murah. Serta tidak dapat berubah bentuk meski terkena air.

c Mempunyai kuat tekan yang cukup tinggi sehingga jika dikombinasikan dengan baja tulangan yang mempunyai kuat tarik tinggi sehingga dapat menjadi satu kesatuan struktur yang tahan tarik dan tahan tekan, untuk itu struktur beton bertulang dapat diaplikasikan atau dipakai untuk pondasi, kolom, balok, dinding, perkerasan jalan, landasan pesawat udara, penampung air, pelabuhan, bendungan, jembatan dan sebagainya.

d Pengerjaan atau workability mudah karena beton mudah untuk dicetak dalam bentuk dan ukuran sesuai keinginan. Cetakan beton dapat dipakai beberapa kali sehingga secara ekonomi menjadi lebih murah.

Walaupun beton mempunyai beberapa kelebihan, beton juga memiliki beberapa kekurangan, menurut (Tjokrodimuljo, 2007) kekurangan beton adalah sebagai berikut ini.

a Bahan dasar penyusun beton agregat halus maupun agregat kasar bermacam-macam sesuai dengan lokasi pengambilannya, sehingga cara perencanaan dan cara pembuatannya bermacam-macam.

b Beton mempunyai beberapa kelas kekuatannya sehingga harus direncanakan sesuai dengan bagian bangunan yang akan dibuat, sehingga cara perencanaan dan cara pelaksanaan bermacam-macam pula.

c Beton mempunyai kuat tarik yang rendah, sehingga getas atau rapuh dan mudah retak. Oleh karena itu perlu diberikan cara-cara untuk mengatasinya, misalnya dengan 
memberikan baja tulangan, serat baja, dan sebagainya agar memiliki kuat tarik yang tinggi.

Pada umunya beton sering digunakan sebagai struktur dalam konstruksi suatu bangunan. Dalam teknik sipil, beton digunakan untuk bangunan fondasi, kolom, balok dan pelat. Menurut Mulyono (2004), terdapat beberapa jenis beton yang dipakai dalam konstruksi suatu bangunan yaitu sebagai berikut ini.

a Beton normal adalah beton yang menggunakan agregat normal.

b Beton bertulang adalah beton yang menggunakan tulangan dengan jumlah dan luas tulangan tanpa pratekan dan direncanakan berdasarkan asumsi bahwa kedua material bekerja secara bersamasama dalam menahan gaya yang bekerja.

c Beton pracetak adalah beton yang elemen betonnya tanpa atau dengan tulangan yang dicetak di tempat yang berbeda dari posisi akhir elemen dalam strukur

d Beton pratekan dalah beton dimana telah diberikan tegangan dalam bentuk mengurangi tegangan tarik potensial dalam beton akibat pemberian beban yang bekerja.

e Beton ringan adalah beton yang memakai agregat ringan atau campuran antara agregat kasar ringan dan pasir alami sebagai pengganti ageragat halus ringan dengan ketentuan tidak boleh melampaui berat isi maksimum beton $1850 \mathrm{~kg} / \mathrm{m}^{3}$ kering udara dan harus memenuhi ketentuan kuat tekan dan kuat tarik beton ringan untuk tujuan struktural.

Kinerja dalam sebuah beton dapat dibuktikan dengan nilai kuat tekan beton. Kuat tekan beton merupakan kemampuan beton untuk menerima beban persatuan luas (Mulyono, 2004). Benda uji beton hancur bila dibebani dengan gaya tekan tertentu yang dihasilkan oleh mesin tekan. Nilai kuat tekan beton seringkali menjadi parameter utama untuk mengenali mutu sebuah konstruksi, karena kuat tekan beton mengidentifikasikan mutu dari sebuah struktur. Kuat tekan beton diwakili oleh tegangan maksimum f'c dengan satuan $\mathrm{kg} / \mathrm{cm}^{2}$ atau $\mathrm{MPa}$ yang bisa didapatkan pada Persamaan 1 (BSN, 1990). Nilai kuat tekan beton umumnya relatif lebih tinggi dibandingkan dengan kuat tariknya, oleh karena itu untuk meninjau mutu beton biasanya secara kasar hanya ditinjau kuat tekannya saja (Tjokrodimuljo, 2007).
TABEL 1. Beberapa jenis beton menurut kuat tekannya (Tjokrodimuljo, 2007)

\begin{tabular}{ll}
\hline \multicolumn{1}{c}{ Jenis Beton } & \multicolumn{1}{c}{ Kuat Tekan } \\
\hline Beton Sederhana & $10 \mathrm{MPa}$ \\
Beton Normal (Beton Biasa) & $15-30 \mathrm{MPa}$ \\
Beton Pra Tegang & $30-40 \mathrm{MPa}$ \\
Beton Kuat Tekan Tinggi & $40-80 \mathrm{MPa}$ \\
Beton Kuat Tekan Sangat Tinggi & $>80 \mathrm{MPa}$ \\
\hline
\end{tabular}

Kuat tekan beton mengalami kenaikan seiring bertambahnya hari sampai umur 28, Menurut (Mulyono 2004) kekuatan tekan beton akan bertambah dengan naiknya umur beton. Kekuatan beton akan naik secara cepat sampai umur 28 hari, tetapi setelah itu kenaikannya akan kecil. Kuat tekan beton dipengaruhi oleh sejumlah faktor, selain oleh perbandingan faktor air semen dan tingkat pemadatannya. Faktor-faktor penting lainnya (Murdock, dkk., 1999) yaitu sebagai berikut ini.

a Jenis semen dan kualitasnya

b Jenis dan bidang permukaan agregat

c Perawatan beton

d Umur beton

$f^{\prime} c=\frac{P}{A}$

dengan:

$$
\begin{array}{ll}
f^{\prime} c & =\text { Kuat tekan Silinder beton }(\mathrm{MPa}) \\
\mathrm{P} & =\text { Beban tekan maksimum }(\mathrm{kg}) \\
\mathrm{A} & =\text { Luas bidang tekan }\left(\mathrm{cm}^{3}\right)
\end{array}
$$

\section{Penyerapan Air}

Menurut Zhang dan Zong (2014) spesimen berbeda dalam penyerapan air permukaan, ada sedikit selisih perbedaan dalam penyerapan air bagian dalam beton. Selain itu, penyerapan air permukaan yang tinggi hanya mengurangi kuat tekan selimut beton. Seluruh kekuatan tekan beton tergantung pada kedua permukaan dan struktur dalam beton. Hal tersebut dapat disimpulkan kekuatan beton tidak dapat dievaluasi oleh penyerapan air. Penyerapan air dapat dihitung dengan Persamaan 2.

$\mathrm{P}_{\mathrm{A}}=\frac{B_{b}-B_{a}}{B_{a}} \times 100$

dengan:

$\mathrm{P}_{\mathrm{A}}=$ Penyerapan air $(\%)$

$\mathrm{B}_{\mathrm{a}}=$ Berat awal beton $(\mathrm{kg})$

$\mathrm{B}_{\mathrm{b}}=$ Berat setelah perendaman $(\mathrm{kg})$ 
Perawatan beton ialah suatu tahap akhir pekerjaan pembetonan, yaitu menjaga agar permukaan beton segar selalu lembab, sejak dipadatkan sampai proses hidrasi cukup sempurna (kira-kira selama 28 hari). Kelembaban permukaan beton itu harus dijaga agar air didalam beton segar tidak keluar. Hal ini untuk menjamin proses hidrasi semen (reaksi semen dan air) berlangsung dengan sempurna. Bila hal ini tidak dilakukan, maka oleh udara panas akan terjadi proses penguapan air dari permukaan beton segar, sehingga air dari dalam beton segar mengalir keluar, dan beton segar kekurangan air untuk hidrasi, sehingga timbul retak-retak pada permukaan betonya (Tjokrodimuljo, 2007).

Pada curing yang akan dilakukan, Air laut sendiri mengandung 3,5\% zat garam, gas-gas terlarut, bahan-bahan organik dan partikel tak terlarut. Zat garam utama yang terdapat dalam air laut adalah klorida sebanyak 55\%, natrium $31 \%$, sulfat $8 \%$, magnesium $4 \%$, kalsium $1 \%$, potassium $1 \%$ dan sisanya terdiri dari bikarbonat, bromide, asam borak, strontium dan florida kurang dari $1 \%$.

Untuk menghindari terjadinya retak-retak pada beton karena proses hidrasi yang terlalu cepat, maka dilakukan perawatan beton dengan cara sebagai berikut ini.

a Menaruh beton segar di dalam ruangan yang lembab.

b Menaruh beton segar di atas genangan air.

c Menaruh beton segar di dalam air.

Menurut BSN (2011) perawatan benda uji beton di laboratorium dapat dilakukan sebagai berikut ini.

a Menutup setelah pekerjaan akhir Untuk menghindari penguapan air dari beton yang belum mengeras, benda segera ditutup setelah pekerjaan akhir, lebih dipilih plat yang tak menyerap dan reaktif atau lembaran plastik yang kuat, awet dan kedap air. Goni basah dapat digunakan untuk menutup, tetapi harus diperhatikan untuk menjaga goni tetap basah hingga benda uji dibuka dari cetakan. Letakan lembaran plastik di atas goni akan melindungi goni untuk tetap basah. Lindungi permukaan luar cetakan papan dari kontak dengan goni basah atau sumber air lainnya sedikitnya untuk 24 jam setelah silinder dicetak. Air dapat menyebabkan cetakan mengembang dan merusakkan benda uji pada umur awal.
Lingkungan perawatan beton. Kecuali bila ada persyaratan lain, semua benda uji dirawat basah pada temperatur $23^{\circ} \mathrm{C} \pm 1,7^{\circ} \mathrm{C}$ mulai dari waktu pencetakan sampai saat pengujian, dengan catatan temperatur dalam pasir basah atau di bawah goni basah atau bahan yang serupa akan selalu lebih rendah dari atmosfir sekitarnya jika penguapan terjadi. Penyimpanan selama 48 jam pertama perawatan harus pada lingkungan bebas getaran. Seperti yang diberlakukan pada perawatan benda uji yang dibuka, perawatan basah berarti bahwa benda uji yang akan diuji harus memiliki air bebas yang dijaga pada seluruh permukaan pada semua waktu. Kondisi ini dipenuhi dengan merendam dalam air jenuh kapur dan dapat dipenuhi dengan penyimpanan dalam ruang jenuh air. Benda uji tidak boleh diletakkan pada air mengalir atau air yang menetes. Rawat silinder beton struktur ringan sesuai dengan standar ini atau sesuai dengan (BSN, 1994).

\section{Metode PeNELITIAN}

Penelitian ini dilakukan di Laboratorium Teknik Sipil Universitas Muhammadiyah Yogyakarta. Adapun material atau bahan yang digunakan dalam penelitian ini adalah sebagai berikut.

a. Agregat halus yang berasal dari Sungai Progo, Kabupaten Kulon Progo

b. Agregat kasar yang digunakan adalah kerikil/split Clereng, Kulon Progo.

c. Semen yang digunakan dalam penelitian ini adalah semen tipe 1 merk Holcim, Gresik, dan Tiga Roda.

d. Air bersih yang digunakan dalam penelitian ini diambil dari Laboratorium Teknologi Bahan,

e. Fly ash yang digunakan dalam penelitian ini diambil dari Laboratorium Teknologi Bahan, Jurusan Teknik Sipil, Fakultas Teknik, Universitas Muhammadiyah Yogyakarta. Pada penelitian ini, Fly Ash yang digunakan sebesar $10 \%$ dari berat Semen.

f. Superplastisizer merk Sikament yang diperoleh dari PT. Sika Indonesia. Pada penelitian ini, superlastisizer yang digunakan sebesar 1\% dari berat semen dan dilakukan pengurangnan penggunaan air.

g. Air Sungai yang berasal dari Sungai Progo untuk pengujian perendaman. 
h. Air laut yang berasal dari pantai Selatan Pulau Jawa untuk pengujian perendaman.

Pelaksanaan penelitian dimulai dari persiapan bahan dan alat dimana perlu dilakukan pengujian sifat material terlebih dahulu terutama pada agregat halus dan kasar. Setelah sifat agregat memenuhi persyaratan yang letah ditetapkan, mix design dibuat dengan kuat tekan rencana $25 \mathrm{MPa}$. Rancangan campuran yang dibuat adalah sebagai berikut ini.

a Variasi pada penelitian ini sebanyak 12 dengan jumlah benda uji sebanyak 108 silinder.

b Sebanyak 6 variasi digunakan untuk beton dengan bahan tambah superplastisizer $1 \%$ dari berat semen. Yang mana setiap variasi memiliki fungsi yang berbeda.

c Sebanyak 6 variasi digunakan untuk beton dengan bahan tambah fly ash $10 \%$ dari berat semen dengan setiap variasi nya memiliki fungsi yang berbeda.

d Pada penelitian ini membandingkan jenis perawatan beton dan merk semen yang digunakan.

Langkah-langkah perancangan campuran beton berdasarkan BSN (2002) yang hasilnya dapat dilihat pada Tabel 2.

Adapun persentase komposisi masing-masing material dapat dilihat pada Gambar 1 dan Gambar 2 berikut ini. Perbedaan dari kedua gambar tersebut terlihat pada prosentase penggunaan fly ash di mana pada Gambar 1 tidak menggunakan fly ash sedangkan pada Gambar 2 terdapat persentase fly ash $2 \%$ dari total berat beton, hal ini menunjukkan inovasi penggunaan fly ash $10 \%$ dari berat semen dapat mengurangi penggunaan semen.

TABEL 2. Komposisi bahan penyusun beton dalam $1 \mathrm{~m}^{3}$

\begin{tabular}{lcc}
\hline \multicolumn{1}{c}{ Bahan } & $\begin{array}{c}\text { Bahan Tambah } \\
\text { Superplastisizer }\end{array}$ & $\begin{array}{c}\text { Bahan } \\
\text { Tambah } \\
\text { Fly Ash }\end{array}$ \\
\hline Semen & 456.79 & 411.11 \\
Air & 166.50 & 185.00 \\
Agregat Kasar & 1365.00 & 1365.00 \\
Agregat Halus & 455.00 & 455.00 \\
Superplastisizer & 4.57 & - \\
Fly Ash & - & 45.68 \\
FAS & 0.36 & 0.41 \\
Total Berat & 2447.86 & 2461.79 \\
\hline
\end{tabular}

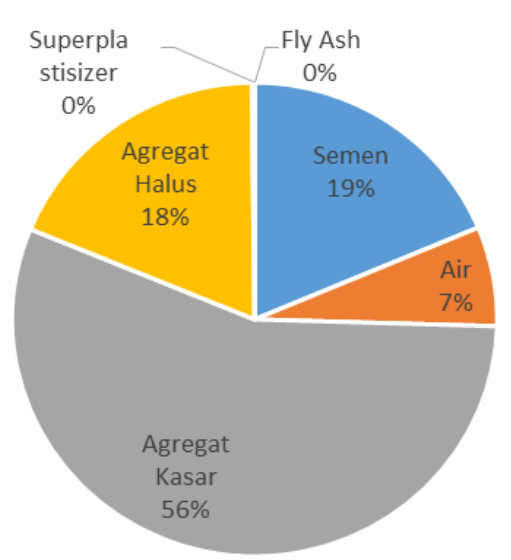

GAMBAR 1. Prosentase mix design untuk campuran dengan bahan tambah superplastisizer

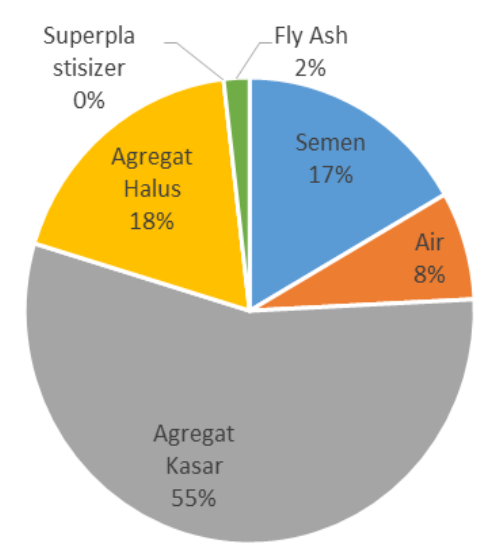

GAMBAR 2. Prosentasi mix design untuk campuran dengan bahan tambah fly ash

Perawatan beton dilakukan bertujuan untuk menjadi proses hidrasi semen berjalan dengan baik dan menghasilkan kuat tekan beton yang sesuai dengan yang direncanakan. Adapun cara perawatan dalam penelitian ini dilakukan dengan 2 variasi menggunakan air sungai dan menggunakan air laut. Dengan jenis air yang berbeda nanti nya diharapkan menghasilkan karakteristik dari setiap beton sehingga dapat menarik kesimpulan yang tepat mengenai bagaimana cara melakukan perawatan beton pada bangunan air.

\section{HASIL DAN PEMBAHASAN}

\section{Hasil Pemeriksaan Agregat}

Sebelum dilakukan pembuatan beton, terlebih dahulu dilakukan pemeriksaan terhadap agregat halu dan kasar. Pada Tabel 3 menunjukkan hasil pemeriksaan pada agregat halus. Pada agregat halus dilakukan pemeriksaan gradasi butiran, modulus halus butir, kadar air, berat jenis, penyerapan air, berat satuan hingga kadar lumpur. Pada pemeriksaan ini dapat disimpulkan bahwa 
agregat halus yang berasal dari Sungai Progo layak digunakan untuk bahan pembuatan beton.

Tabel 4 menjelaskan hasil pemeriksaan agregat kasar, hasil yang diperoleh menunjukkan bahwa seluruh persyaratan yang ditentukan bisa dipenuhi agregat yang berasal dari Clereng, Kulon Progo. Adapun pemeriksaan yang dilakukan berupa pengecekan kadar air, berat jenis, penyerapan air, berat satuan, kadar lumpur dannilai keausan yang diperoleh dari hasil uji los angeles.

Hasil pemeriksaan ini pun tidak jauh berbeda dengan hasil pengujian sebelumnya yang dilakukan oleh (Ervianto dkk, 2016) dan (Ikhsan dkk, 2016) yang juga melakukan pemeriksaan sifat agregat halus dari Sungai Progo dan Agregat Kasar dari Clereng, Kabupaten Kulon Progo.

\section{Pemeriksaan Nilai Slump}

Pengujian slump dilakukan untuk mengetahui tingkat kemudahan pada pengerjaan beton seperti terlihat pada gambar 3. Beton dengan bahan tambah fly ash menghasilkan nilai workability cenderung lebih kecil. Pada semen holcim menghasilkan nilai slump $2,20 \mathrm{~cm}$, tiga roda sebesar $2,15 \mathrm{~cm}$ dan semen gresik menghasilkan nilai slump 2,25 cm. Sedangkan beton dengan bahan tambah superplastisizer menghasilkan nilai workability yang cukup tinggi yaitu dengan semen holcim sebesar $20,50 \mathrm{~cm}$, semen tiga roda $18,25 \mathrm{~cm}$ dan semen gresik 19,50\%. Dari nilai workability ini dapat disimpulkan bahwa bahan tambah yang digunakan merupakan 2 material yang sangat berbeda sifat nya dan sangat mempengaruhi tingkat pengerjaan dari beton itu sendiri.

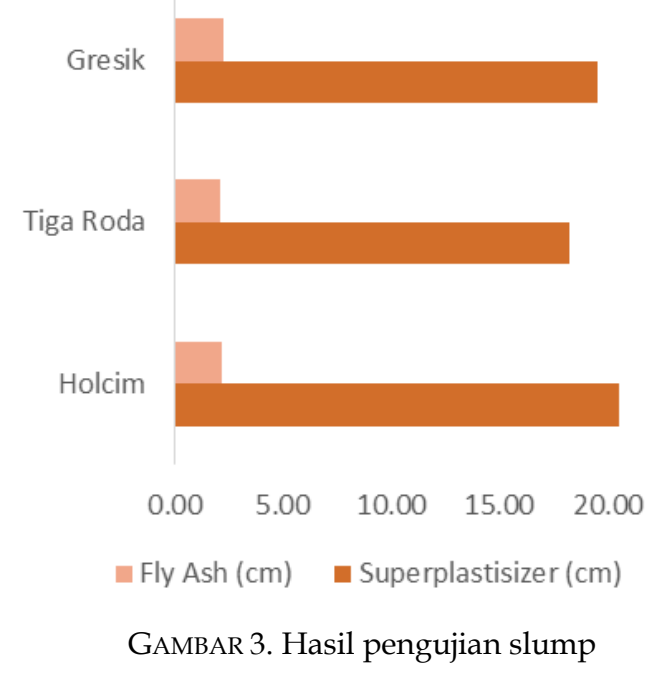

TABEL 3. Hasil pemeriksaan agregat halus

\begin{tabular}{lc}
\hline \multicolumn{1}{c}{ Jenis Pengujian } & Hasil \\
\hline Gradasi Butiran & 4 (Kasar) \\
Modulus Halus Butir & 2.66 \\
Kadar Air $(\%)$ & 1.50 \\
Berat Jenis & 2.42 \\
Penyerapan Air $(\%)$ & 11.00 \\
Berat Satuan $\left(\mathrm{g} / \mathrm{cm}^{3}\right)$ & 1.32 \\
Kadar Lumpur $(\%)$ & 3.13 \\
\hline
\end{tabular}

TABEL 4. Hasil pemeriksaan agregat kasar

\begin{tabular}{lc}
\hline \multicolumn{1}{c}{ Jenis Pengujian } & Hasil \\
\hline Kadar Air (\%) & 0.67 \\
Berat Jenis & 2.69 \\
Penyerapan Air (\%) & 1.13 \\
Berat Satuan $\left(\mathrm{g} / \mathrm{cm}^{3}\right)$ & 1.55 \\
Kadar Lumpur (\%) & 0.12 \\
Nilai Keausan $(\%)$ & 25.66 \\
\hline
\end{tabular}

\section{Hasil Pemeriksaan Kuat Tekan Beton}

Hasil pemeriksaan kuat tekan beton dapat dilihat pada Tabel 5 berikut ini dimana beton di uji pada umur 7, 14 dan 28 hari. Adapun perbedaan dari masing-masing variasi adalah sebagai berikut.

1) Bahan Tambah Superplastisizer dengan semen Holcim dan perawatan Air Sungai.

2) Bahan Tambah Superplastisizer dengan semen Tiga Roda dan perawatan Air Sungai.

3) Bahan Tambah Superplastisizer dengan semen Gresik dan perawatan Air Sungai

4) Bahan Tambah Superplastisizer dengan semen Holcim dan perawatan Air Laut.

5) Bahan Tambah Superplastisizer dengan semen Tiga Roda dan perawatan Air Laut.

6) Bahan Tambah Superplastisizer dengan semen Gresik dan perawatan Air Laut.

7) Bahan Tambah Fly Ash dengan semen Holcim dan perawatan Air Sungai.

8) Bahan Tambah Fly Ash dengan semen Tiga Roda dan perawatan Air Sungai.

9) Bahan Tambah Fly Ash dengan semen Gresik dan perawatan Air Sungai.

10) Bahan Tambah Fly Ash dengan semen Holcim dan perawatan Air Laut.

11) Bahan Tambah Fly Ash dengan semen Tiga Roda dan perawatan Air Laut.

12) Bahan Tambah Fly Ash dengan semen Gresik dan perawatan Air Laut. 
Pada Tabel 5 merupakan hasil dari pengujian seluruh benda ujia dengan setiap umur nya. Serta pada Gambar 4 merupakan hasil hubungan masing-masing variasi benda uji dengan kuat tekan dalam setiap umur nya. Dari data ini dapat disimpulkan bahwa dengan variasi 5 merupakan hasil dengan kuat tekan tertinggi. Variasi 5 merupakan komposisi dari beton normal yang di inovasikan dengan bahan tambah superplastisizer menggunakan semen tiga roda dan dilakukan perawatan menggunakan air laut.

Pada Gambar 5 (a) menjelaskan hubungan antara waktu perawatan dengan kuat tekan beton dengan menggunakan bahan tambah superplastisizer. Dari hasil ini diperoleh bahwa kuat tekan tertinggi pada variasi 5 yaitu dengan menggunakan semen tiga roda dan perendaman menggunakan air laut. Sedangkan pada Gambar 5 (b) merupakan hubungan antara waktu perendaman dengan kuat tekan beton menggunakan bahan tambah fly ash, hasil yang diperoleh pada penelitian ini bahwa semen holcim dengan bahan tambah fly ash serta dengan perawatan menggunakan air laut memperoleh kuat tekan tertinggi.

TABEL 5. Hasil Pengujian Kuat Tekan Beton

\begin{tabular}{ccccccccccccc}
\hline Umur & \multicolumn{10}{c}{ Variasi } \\
\cline { 2 - 14 } (Hari) & 1 & 2 & 3 & 4 & 5 & 6 & 7 & 8 & 9 & 10 & 11 & 12 \\
\hline 7 & 14.43 & 15.14 & 9.60 & 15.54 & 19.94 & 20.49 & 12.04 & 9.43 & 9.98 & 13.24 & 7.20 & 12.15 \\
7 & 22.69 & 15.87 & 15.93 & 13.79 & 23.42 & 15.37 & 10.11 & 12.88 & 9.48 & 13.99 & 10.98 & 11.24 \\
7 & 23.71 & 15.87 & 15.19 & 15.57 & 22.12 & 18.52 & 13.46 & 13.11 & 11.52 & 9.56 & 18.03 & 12.66 \\
Mean & $\mathbf{2 0 . 2 8}$ & $\mathbf{1 5 . 6 3}$ & $\mathbf{1 3 . 5 7}$ & $\mathbf{1 4 . 9 7}$ & $\mathbf{2 1 . 8 3}$ & $\mathbf{1 8 . 1 3}$ & $\mathbf{1 1 . 8 7}$ & $\mathbf{1 1 . 8 1}$ & $\mathbf{1 0 . 3 3}$ & $\mathbf{1 2 . 2 6}$ & $\mathbf{1 2 . 0 7}$ & $\mathbf{1 2 . 0 2}$ \\
\hline 14 & 23.71 & 17.51 & 19.08 & 17.32 & 23.88 & 21.92 & 18.10 & 14.96 & 11.53 & 17.78 & 18.39 & 13.43 \\
14 & 24.69 & 19.16 & 18.96 & 24.14 & 24.58 & 22.11 & 18.50 & 14.01 & 12.15 & 20.38 & 18.66 & 15.47 \\
14 & 25.41 & 17.24 & 16.59 & 21.09 & 32.11 & 22.33 & 15.36 & 13.95 & 13.27 & 19.71 & 21.21 & 16.05 \\
Mean & $\mathbf{2 4 . 6 0}$ & $\mathbf{1 7 . 9 7}$ & $\mathbf{1 8 . 2 1}$ & $\mathbf{2 0 . 8 5}$ & $\mathbf{2 6 . 8 6}$ & $\mathbf{2 2 . 1 2}$ & $\mathbf{1 7 . 3 2}$ & $\mathbf{1 4 . 3 1}$ & $\mathbf{1 2 . 3 2}$ & $\mathbf{1 9 . 2 9}$ & $\mathbf{1 9 . 4 2}$ & $\mathbf{1 4 . 9 8}$ \\
\hline 28 & 25.42 & 20.36 & 25.71 & 30.96 & 32.36 & 24.00 & 18.73 & 27.64 & 21.73 & 24.28 & 24.40 & 16.62 \\
28 & 31.82 & 20.57 & 28.44 & 25.49 & 33.81 & 23.87 & 21.25 & 15.56 & 15.28 & 21.64 & 23.86 & 27.08 \\
28 & 29.38 & 24.11 & 31.01 & 30.82 & 35.71 & 27.23 & 21.14 & 19.36 & 25.71 & 26.18 & 22.27 & 23.02 \\
Mean & $\mathbf{2 8 . 8 7}$ & $\mathbf{2 1 . 6 8}$ & $\mathbf{2 8 . 3 9}$ & $\mathbf{2 9 . 0 9}$ & $\mathbf{3 3 . 9 6}$ & $\mathbf{2 5 . 0 3}$ & $\mathbf{2 0 . 3 7}$ & $\mathbf{2 0 . 8 5}$ & $\mathbf{2 0 . 9 1}$ & $\mathbf{2 4 . 0 3}$ & $\mathbf{2 3 . 5 1}$ & $\mathbf{2 2 . 2 4}$ \\
\hline
\end{tabular}

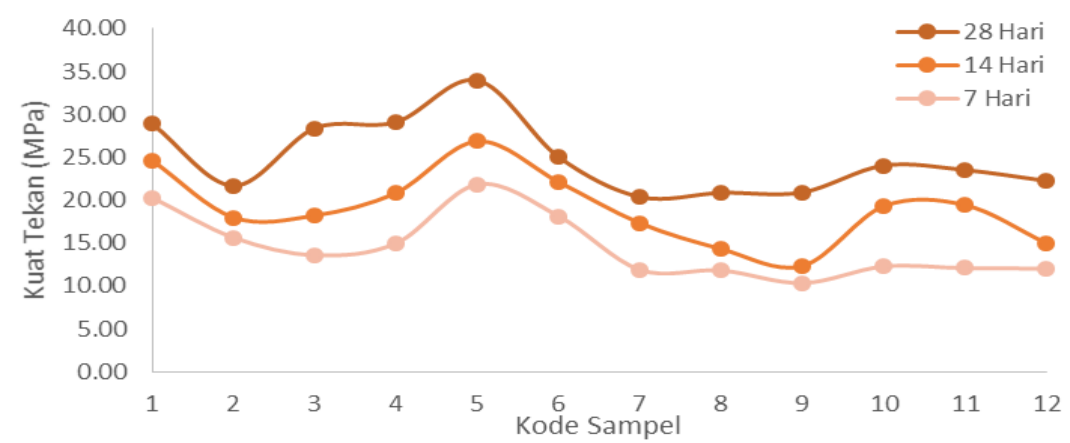

GAMBAR 4. Hasil Pengujian kuat tekan beton umur 7, 14 dan 28 Hari
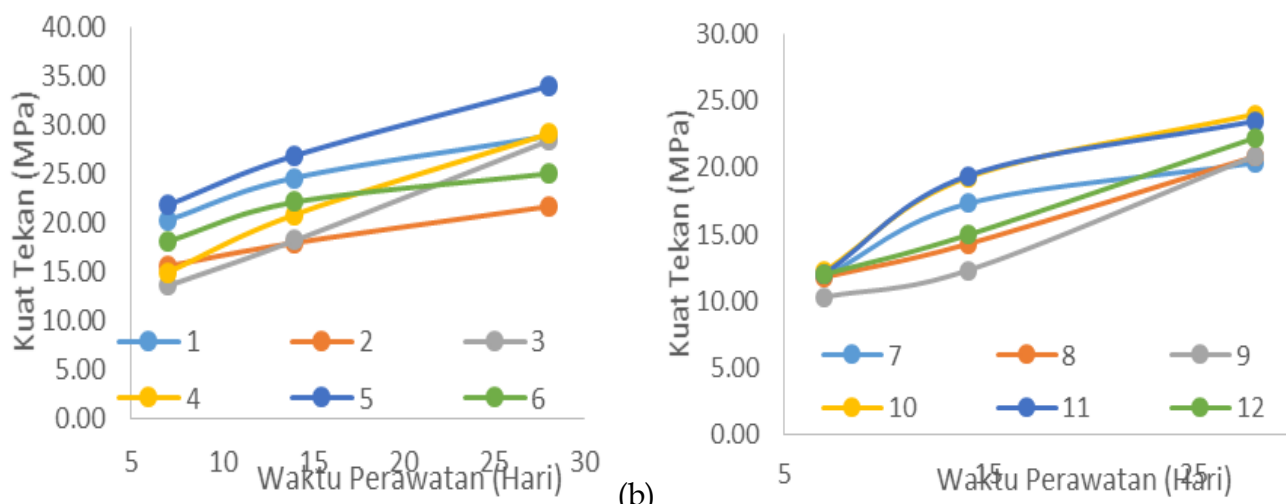

(a)

GAMBAR 5. (a) hubungan waktu perawatan dengan kuat tekan beton dengan bahan tambah superplastisizer; (b) hubungan waktu perawatan dengan kuat tekan beton dengan bahan tambah fly ash 
Gambar 6 menjelaskan mengenai perbandingan kuat tekan beton menggunakan bahan tambah superplastisizer berdasarkan jenis perawatan. Pada Gambar 6 tersebut terlihat jelas bahwa beton dengan jenis Holcim dan Tiga Roda memiliki kuat tekan yang lebih tinggi dengan menggunakan perawatan Air Laut sedangkan pada semen Gresik nilai kuat tekan yang di hasilkan lebih tinggi pada beton dengan perawatam air sungai.

Pada Gambar 7 menjelaskan perbandingan kuat tekan beton menggunakan bahan tambah fly ash berdasarkan jenis perawatan dengan air laut dan air sungai. Berdasarkan Gambar 7 dapat disimpulkan bahwa dengan campuran yang sama, beton dengan perawatan air laut menghasilkan kuat tekan yang lebih besar dibandingkan dengan beton perawatan air sungai.Pada Gambar 8 menjelaskan hubungan kuat tekan beton dengan perendaman air sungai. Pada Gambar 8 dapat disimpulkan menggunakan bahan tambah superlpastisizer menghasilkan kuat tekan yang lebih tinggi dari pada penggunaan fly ash, hal ini dikarenakan dalam penggunaan superlpastisizer tidak dilakukan pengurangan komposisi semen serta dilakukan pengurangan jumlah air yang digunakan sehingga faktor air semen yang digunakan juga menjadi semakin kecil.

Gambar 8 dan Gambar 9 menunjukkan bahwa semakin kecil faktor air semen semakin besar kemungkinan menghasilkan kuat tekan beton yang lebih baik pula. Selain itu, dengan menggunakan superplastiziser menghasilkan nilai workability yang tinggi pula sehingga tingkat pengerjaannya lebih mudah dibandingkan dengan menggunakan bahan tambah fly ash.

Beton dengan menggunakan fly ash menghasilkan kuat tekan yang lebih kecil karena sifat fly ash yang hanya mirip dengan semen akan tetapi tidak benar-benar sama seperti semen, selain itu bentuk fly ash yang sangat kering dan lebih kasar dibandingkan semen sangat memungkinkan fly ash menyerap air lebih banyak dan menghasilkan pro pori lebih banyak.

\section{Pemeriksaan Nilai Penyerapan}

Nilai penyerapan dilakukan untuk mengetahui jumla air yang bisa menyerap kedalam beton. Pada Gambar 10 dan Gambar 11 menjelaskan bahwa nilai penyerapan pada umur 28 hari tertinggi dialami oleh beton dengan perawatan menggunakan air laut. Tentunya hal ini menjadi topik penelitian yang lebih lanjut agar dapat mengurangi tingkat penyerapan pada beton karena semakin besar nilai penyerapan pada beton akan dapat merusak tulangan pada beton apabila beton diaplikasikan bada struktur beton bertulang di bangunan air.

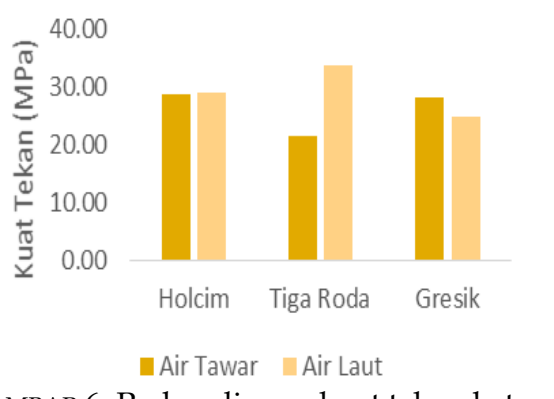

GAMBAR 6. Perbandingan kuat tekan beton menggunakan bahan tambah superplastisizer berdasarkan jenis perawatan

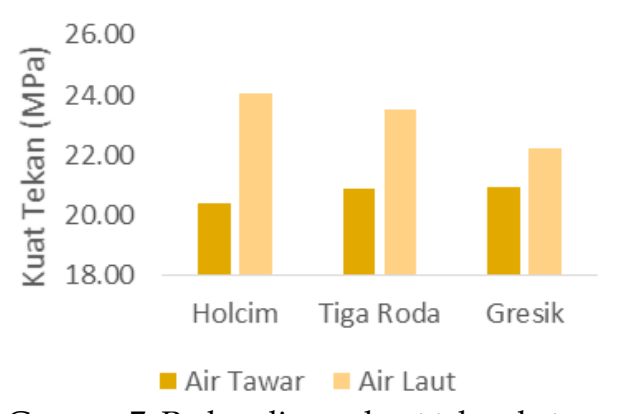

GAMBAR 7. Perbandingan kuat tekan beton menggunakan bahan tambah fly ash berdasarkan jenis perawatan

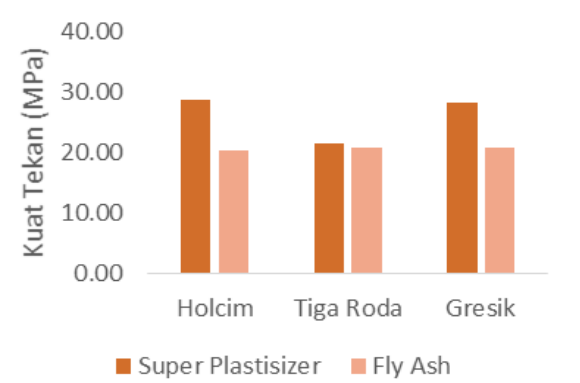

GAMBAR 8. Perbandingan kuat tekan beton dengan perawatan air sungai berdasarkan bahan tambah

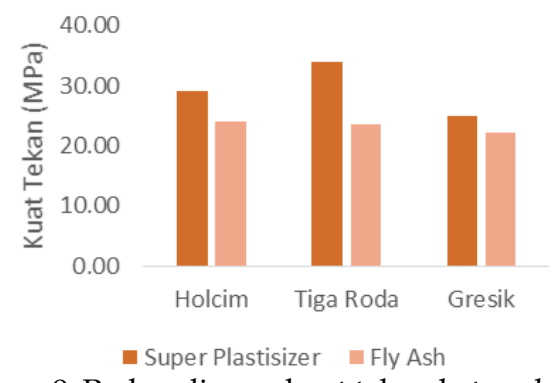

GAMBAR 9. Perbandingan kuat tekan beton dengan perawatan air laut berdasarkan bahan tambah 
A. Pujianto, et al./Semesta Teknika, Vol. 22 No. 2, 112-122, November 2019
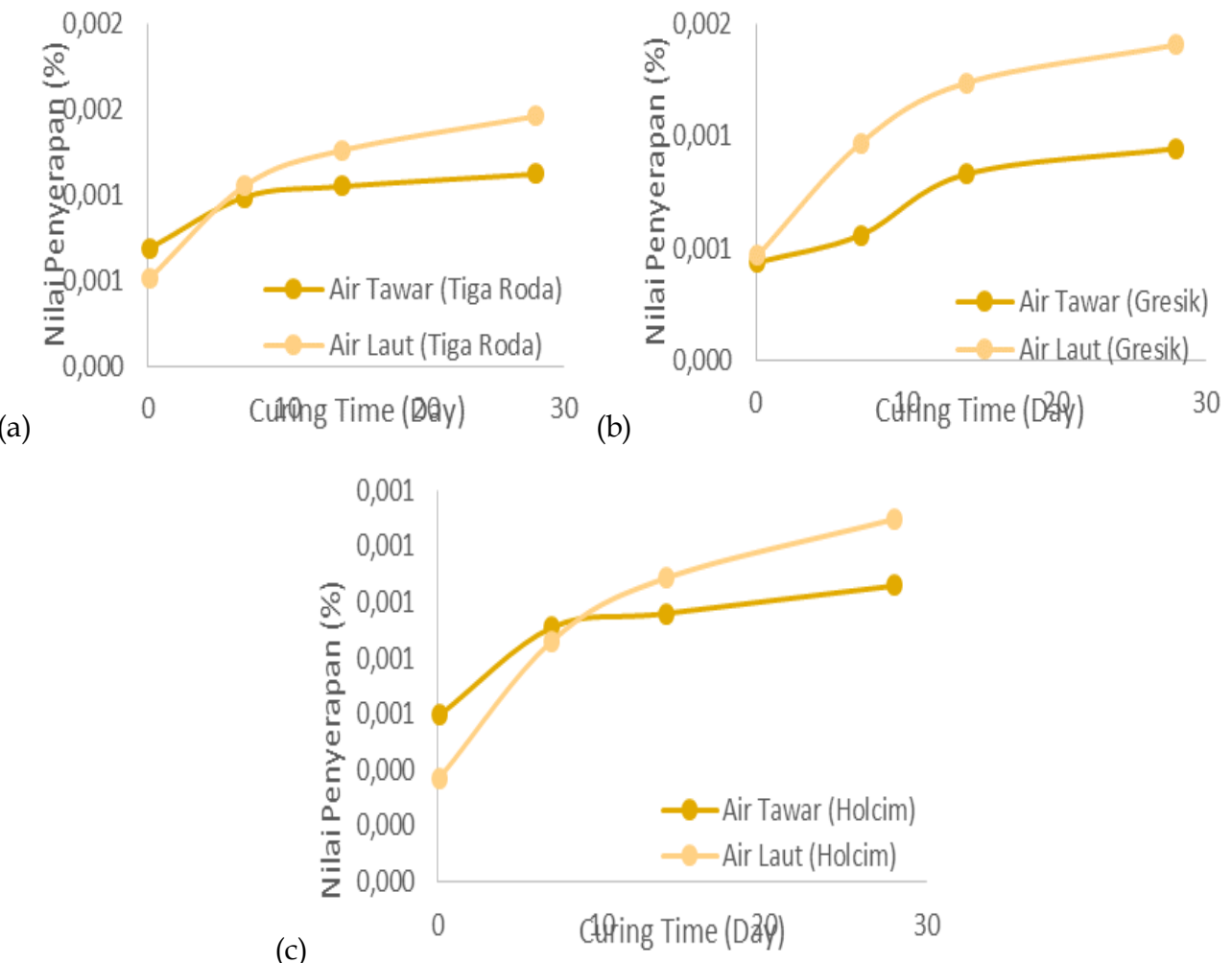

GAMBAR 10. Hubungan waktu perawatan dengan nilai penyerapan pada beton dengan bahan tambah superplastisizer pada (a) semen holcim; (b) semen tiga roda; (c) semen gresik

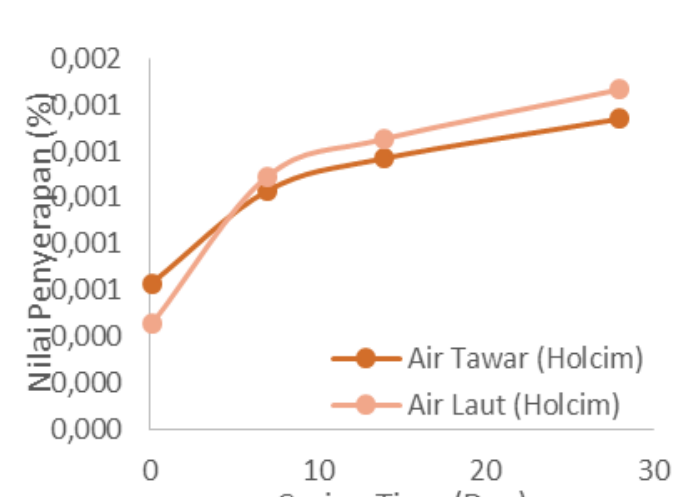

(a) Curing Time (Day) (b) $\quad$ (b)
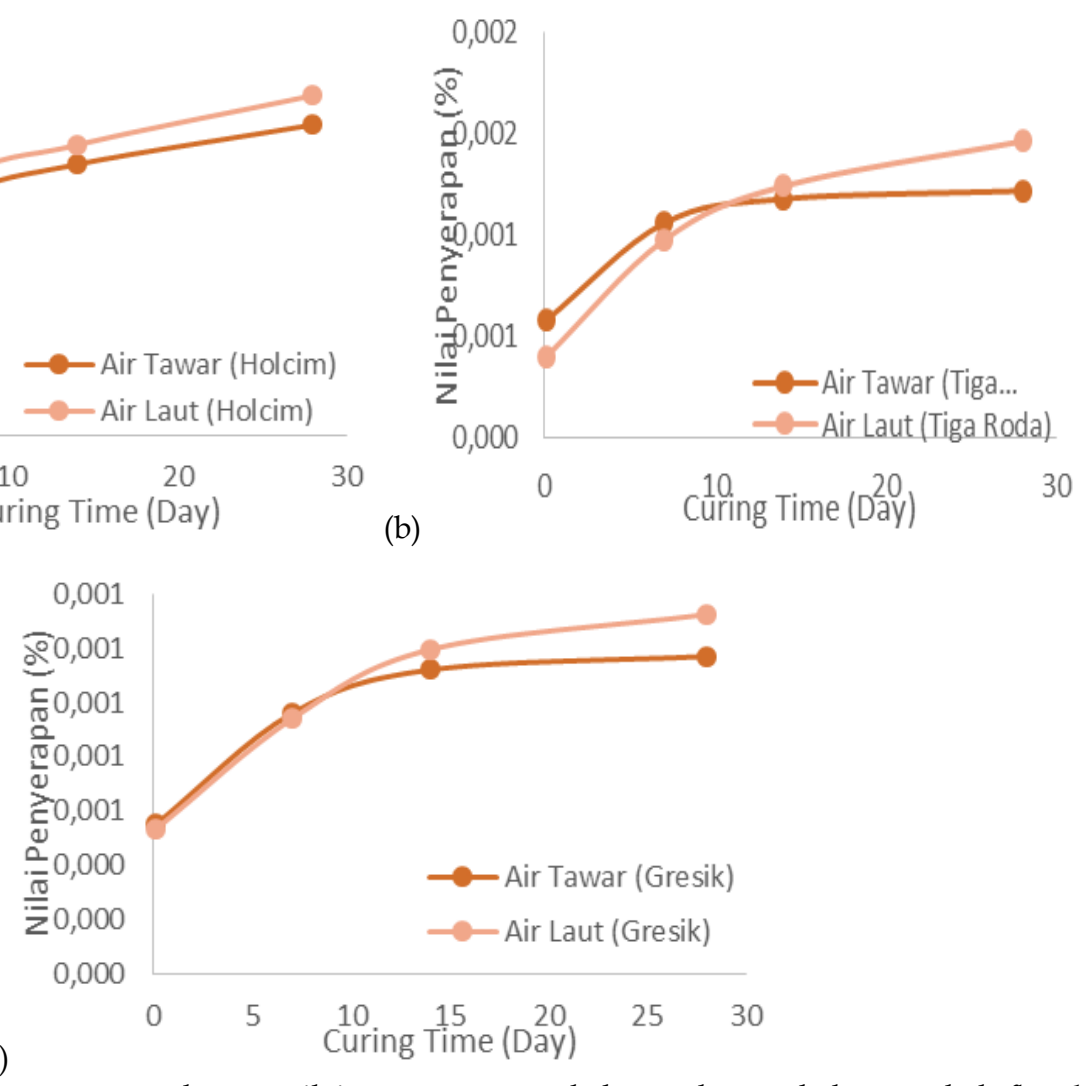

GAMBAR 11. Hubungan waktu perawatan dengan nilai penyerapan pada beton dengan bahan tambah fly ash pada

(a) semen holcim; (b) semen tiga roda; (c) semen gresik 


\section{KESIMPULAN}

Dari hasil dan pembahasan dapat ditarik kesimpulan dengan penelitian kuat tekan beton dengan variasi perendaman air laut dan air sungai adalah nilai workability menggunakan bahan tambah superplasticizer lebih tinggi daripada beton menggunakan fly ash. Perawatan beton menggunakan air laut menghasilkan kuat tekan tertinggi pada Semen Tiga Roda dengan bahan tambah superplatisizer yaitu dengan kuat tekan sebesar 33,96 MPa. Perawatan beton menggunakan air sungai menghasilkan kuat tekan tertinggi pada beton dengan jenis Holcim dengan bahan tambah superplastisizer yaitu dengan kuat tekan sebesar 28,87 MPa. Beton dengan menggunakan bahan tambah fly ash hanya menghasilkan kuat tekan tertinggi sebesar 24,03 MPa dengan merk semen Holcim. Nilai penyerapan pada umur beton 28 hari secara keseluruhan pada beton dengan perendaman air laut lebih tinggi dibandingkan dengan air sungai.

\section{DAFTAR PUSTAKA}

Badan Standarisasi Nasional. (1990). SK SNI 03-1974-1990: Metode Pengujian Kuat Tekan Beton. Dinas Pekerjaan Umum. Jakarta.

Badan Standarisasi Nasional. (1994). SNI 033402-1994: Metode Pengujian Berat Isi Beton Ringan Struktur. Dinas Pekerjaan Umum. Jakarta.

Badan Standarisasi Nasional. (2002). SNI 032847-2002: Tata Cara Perhitungan Struktur Beton untuk Bangunan Gedung. Dinas Pekerjaan Umum. Jakarta.

Badan Standarisasi Nasional. (2011). SNI 2493-2011: Tata Cara Pembuatan dan Perawatan Benda Uji Beton di Laboratorium. Dinas Pekerjaan Umum. Jakarta.

Ervianto, M., Saleh, F., Prayuda, H. (2016). Kuat Tekan Beton Mutu Tinggi Menggunakan Bahan Tambah Abu Terbang (Fly ash) dan Zat Adiktif (Bestmittel). Sinergi Vol 20 No. 3. Pp 199-206.

Hendriyani, R., Pratiwi, R., Aprilianus, Y. 2016. Pengaruh Jenis Air Pada Perawatan Beton Terhadap Kuat Tekan
Beton. Tugas Akhir Jurusan Teknik Sipil Universitas Balikpapan. Balikpapan.

Hunggurami, E., Utomo, S., Wadu, A. (2014). Pengaruh Masa Perawatan (Curing) Menggunakan Air Laut Terhadap Kuat Tekan dan Absorpsi Beton. Jurnal Teknik Sipil Universitas Nusa Cendana, Kupang.

Ikhsan, M.N., Prayuda, H., Saleh, F. (2016). Pengaruh Penambahan Pecahan Kaca Sebagai Bahan Pengganti Agregat Halus dan Penambahan Fiber Optik Terhadap Kuat Tekan Beton Serat. Jurnal Ilmiah Semesta Teknika Vol 19 No 2. Pp 148156.

Mulyono, T. (2004). Teknologi Beton. Penerbit Andi. Yogyakarta.

Murdock, L. J., Brook, K. M. (1999). Bahan dan Praktek Beton. Penerbit Erlangga. Jakarta.

Prayuda, H., Pujianto, A. (2018). Pengaruh Perawatan (Curing Perendaman Air Laut dan Air Tawar Terhadap Kuat Tekan Beton, Jurnal Ilmiah Teknik Sipil, Vol 22 (2). Pp. 130-139.

Samekto, W., Rahmadiyanto, C. (2001). Teknologi Beton. Penerbit Kanisius. Yogyakarta.

Tjokrodimuljo, K. (2007). Teknologi Beton. Keluarga Mahasiswa Teknik Sipil Universitas Gadjah Mada. Yogyakarta.

Zhang, S.P., Zong, L. (2014). Evaluation of Relationship between Water Absorption and Durability of Concrete Materials. Hindawi. China.

PENULIS:

As'at Pujianto

Program Studi Teknik Sipil, Fakultas Teknik, Universitas Muhammadiyah Yogyakarta, Jalan Lingkar Selatan, Tamantirto, Kasihan, Bantul, Yogyakarta 55183.

Email: pujiantoasat@umy.ac.id

Hakas Prayuda

Program Studi Teknik Sipil, Fakultas Teknik, Universitas Muhammadiyah Yogyakarta, Jalan 
Lingkar Selatan, Tamantirto, Kasihan, Bantul, Yogyakarta 55183.

Email: hakasprayuda@umy.ac.id

\section{Berkat Cipta Zega}

Jurusan Teknik Sipil, Fakultas Teknik, Universitas Negeri Surabaya, Jalan Ketintang, Surabaya

Email: berkatzega@unesa.ac.id

\section{Besty Afriandini}

Program Studi Teknik Sipil, Fakultas Teknik, Universitas Muhammadiyah Purwokerto, Jalan KH. Ahmad Dahlan, Dusun III, Dukuhwaluh, Kembaran, Banyumas, Jawa Tengah

Email: bestyafriandini24@gmail.com 